\title{
FEATURE Grass-shed: Place and process for catalyzing perennial grass bioeconomies and their potential multiple benefits
}

\author{
Carol L. Williams, Paul Charland, Gary Radloff, David Sample, and Randall D. Jackson
}

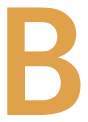

urgeoning human populations are increasing the demand for land, water, energy, food, and natural resources. Agricultural practices that use annual crop monocultures and high amounts of external inputs, such as synthetic fertilizers and pesticides, have led to considerable increases in production. However, reliance on these low-diversity/ high-external-input systems has negatively impacted human health and natural resources (Goolsby et al. 2001; Hazell and Wood 2008). There is also a growing realization that effective conservation of resources, wildlife, and biodiversity will not occur solely through "land sparing" approaches (Matson and Vitousek 2006; Perfecto and Vandermeer 2010). Hence, there is increased need for achieving productivity and conservation simultaneously on working lands, i.e., multifunctionality (Jordan and Warner 2010).

Expanded grassland commerce offers one potential solution to the production and conservation challenge. Bioenergy has been identified as an important tool for achieving renewable energy, rural development, and conservation goals for soil, water, and wildlife (Rajagopal and Zilberman 2007). Low-input, diverse grasslands are a promising source of feedstocks for bioenergy and can deliver conservation benefits (Tilman et al. 2006). Although US agriculture and energy policies have aimed

Carol L. Williams is a research scientist in the Department of Agronomy and the Wisconsin Energy Institute, University of Wisconsin, Madison, Wisconsin. Paul Charland is a wildland urban interface coordinator for the Leopold Wetland Management District, US Fish and Wildlife Service, Portage, Wisconsin. Gary Radloff is director of the Midwest Energy Policy Analysis, Wisconsin Energy Institute, University of Wisconsin, Madison, Wisconsin. David Sample is a grassland community ecologist for the Bureau of Science Services, Wisconsin Department of Natural Resources, Madison, Wisconsin. Randall D. Jackson is a professor in the Department of Agronomy and the US Department of Energy Great Lakes Bioenergy Research Center, University of Wisconsin, Madison, Wisconsin. to encourage development of cellulosic bioenergy from sources such as perennial grasses (EISA 2007), this development has been sluggish. As a result, potential multiple benefits have been foregone, and lack of at-scale systems has prevented empirical study of intensification of grassland production. Cellulosic bioenergy is faced with a chicken-and-egg dilemma where investors in biomass conversion technologies and infrastructure are reluctant to engage until there is sufficient biomass supply, and biomass producers are unwilling to invest in new crops and production systems until there is sufficient demand. Overcoming this market inertia may require novel intervention (i.e., nongovernmental) for reducing risk and uncertainty in enterprise development and biomass supply (McCormick and Kaberger 2005; Taylor et al. 2013).

A potentially transformative approach to grass-based bioenergy expansion is place-based collaborative design, implementation, and monitoring of perennial grass supply and value chains anchored to commercial-scale biomass conversion facilities. We present an idealized model of collaborative intervention and its application within a target area, together called a "grass-shed."We contend that when carefully planned and managed, grass-sheds will increase landscape multifunctionality as well as support conservation goals of protected lands within them.

\section{TARGETED COLLABORATIVE INTERVENTION}

Simply stated, a grass-shed is a geographic area within which perennial grass production and use is planned and implemented. Similar to a foodshed or a fuelshed, a grass-shed is a planning unit for specific types of goods and services. In this case, the goods are perennial grass biomass and products derived therefrom, and services include ecosystem services (MEA 2005). Agriculture, however, is inherently complex and includes risk. It involves decision-making in the face of uncertainty, diverging opinions, and contested social val- ues (Nassauer 1995). Moreover, managing bioeconomic transitions may be intractable via top-down, command-and-control, and traditional technological problem solving approaches (Chakraborty 2011; Holling and Meefe 1996; Warner 2008). The challenges of bioeconomic transition, therefore, require social innovation to overcome market inertia (Kircher 2012).

Researchers and community leaders point to the need for new approaches to policy and planning to address complex, multiscale interactions among ecological and social drivers in agricultural production, and for including farmer-, field-, and community-level processes in problem framing and solution seeking (Atwell et al. 2009, 2010, 2011; Solomon 2010). Collaboration across disciplines and among researchers and practitioners is thus gaining recognition as an important means for addressing innovation needs like those for bioeconomic development (Ansell and Gash 2007; Bammer 2008; Armitage et al. 2009). The grass-shed model contains two features for addressing these needs. The first key characteristic is defining the geographic location and extent of a grass-shed. The boundaries of a grassshed are defined by relationships among people and their supporting institutions rather than by biogeophysical boundaries or an arbitrary political boundary. The boundary may, in fact, be fluid and change over time. The flow of grass materials within a grass-shed are also defined by socioeconomic processes (e.g., market forces). The second key characteristic of a grass-shed is use of collaborative processes and adaptive management principles for sustainable bioeconomic development. That is, a grass-shed is as an organizing frame for socioecological intervention (i.e., informed and directed change in biogeophysical systems and associated socioeconomic systems for a specific set of goals and objectives [Hobbs et al. 2011]).

Many models of collaboration could be suited to a grass-shed. Transdisciplinary approaches to collaboration, however, offer particular promise. Transdisciplinary 
strategies foster collaboration among disciplinary experts and nondisciplinary practitioners (e.g., researchers and farmers).As distinguished from interdisciplinary and multidisciplinary processes, transdisciplinarity processes promote synthesis of perspectives and methodologies in order to support coproduction of knowledge and produce outcomes for public good versus private gain solely (Gray 2008; Hirsch Hadorn et al. 2008; Ravetz 2006). Transdisciplinarity is a good candidate for facilitating the generation, application, and evaluation of evidence-based solutions for expansion of grass commerce.

The ultimate goal of the grass-shed approach is to foster change. Social learning (Schusler et al. 2010) and learning by doing can reduce risk associated with change while helping build capacity and social infrastructure required for change (Armitage et al. 2009; Barreteau et al. 2010). As such, the grass-shed approach should be considered as a think- and dotank to reduce the time, financial resources, and expertise required of individual participants to gain entry into nascent bioeconomies. Adaptive management principles offer tremendous value to support these aims (Holling and Meffe 1996). For example, collaborators could consider new and expanded uses of grass biomass in the context of other land uses and development needs (e.g., wildlife habitat protection, pasture, annual commodity crop production, etc.). They could also consider joint ventures and pilot initiatives for strategically introducing change, evaluating performance, and responding adaptively. Many techniques and tools, such as dynamic systems modeling, scenariobuilding, and landscape visualizations, are available to aid these processes (Nassauer and Corry 2004; Shafie-Khah et al. 2013).

\section{GRASS-SHED DEVELOPMENT}

Like all participatory and collaborative ventures, the development pathway of a grass-shed will be shaped by those who participate, as well as local and regional circumstances and availability of resources (Buccholz et al. 2007). Nonetheless, our idealized model of grass-shed development includes four stages: incubation, start-up, expansion, and maturity (fig-

\section{Figure 1}

Idealized development of a grass-shed in four stages of collaborative planning and action over time.

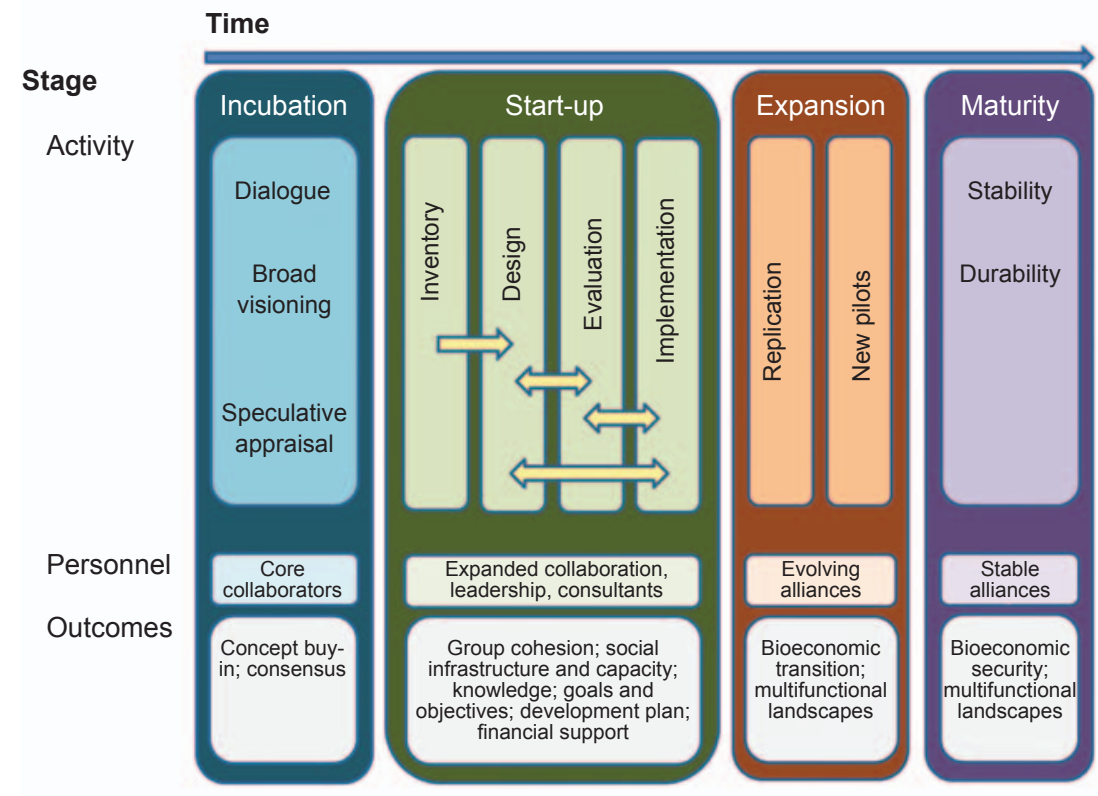

ure 1). During the incubation stage, a relatively small group of potential collaborators - who may or may not be from the same sector-engage in dialogue regarding shared values or concerns, and broad visioning. During this stage, potential collaborators make speculative appraisals of capacity for supporting new or expanded perennial grass economies. Here, appraisal is based on general perceptions and informal knowledge. If consensus is favorable, the group seeks out other partners and moves on to the start-up stage.

Start-up is a multifaceted stage that includes the tasks of taking resource inventory; identifying opportunities and barriers; imagining model systems of grass production, marketing, and utilization; and identifying a range of actions or projects to undertake. Collaborators consider a variety of goals and objectives such as production targets (i.e., supply volume and locations); supply chain structure and function (e.g., value-addition); biomass end-uses; and the types of social, economic, environmental, and ecological benefits desired as outcomes. This process continues iteratively until collaborators are satisfied their design represents a future scenario they wish to pursue. Collaborators then priori- tize activities and projects and implement first actions. As necessary, and on the basis of feedback, projects and the collaboration itself are modified to better achieve mission success and move toward the expansion stage.

Expansion is a stage of replicating proven ideas and actions while continuing to test new ones. In this stage, the network of collaborators continues their support for existing activities and considers new projects. The methods and processes of this stage are very similar to that of startup (e.g., implementing, monitoring, and retooling). However, in this stage there is the benefit of knowing more about what to expect and an ability to approach difficulties with an intact network of knowledge and support.

Maturity is the stage of self-perpetuation and long-term maintenance of existing activities and projects. During this stage, collaborators may decide whether to continue in collaborative association or to maintain activities and projects more independently. An essential outcome of the maturity stage is broad-scale appreciation of the benefits of a well-designed and functioning grass-shed. 


\section{Figure 2}

Idealized development of a grass-shed in four stages of collaborative planning and action over time.

Legal obligations and limitations of US Fish and Wildlife Service district and regional leadership

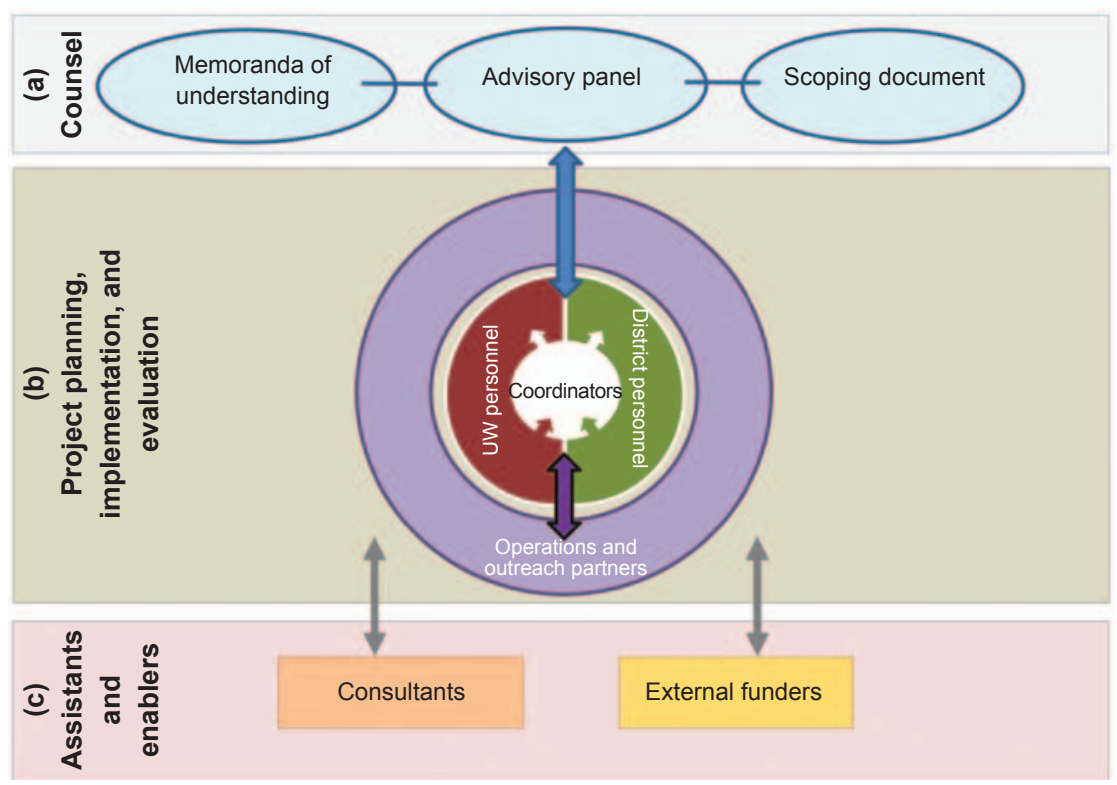

To be successful, a grass-shed must be robust and resilient.Appropriate leadership is therefore essential for aligning grass-shed collaborators cognitively and behaviorally into a larger mission, convincing them that to work in alliance is preferable to working independently (Mollinga 2010). To deliver satisfactory results over time, there must be durability in a collaboration (Austin 2000). Durability depends on the production of continuous value for collaborators and availability of resources for maintaining essential functions of the collaboration. Collective activity is of value when the dependencies imposed by them are outweighed by the advantages they provide. This value can be demonstrated through measurements made on progress. Hanleybrown et al. (2012) describe the presence of a "backbone organization" as an essential element for holding collective initiatives together. Without a dedicated staff with very specific skills to anchor collaborative efforts, many such efforts fail. A new organization is not always necessary to serve the backbone role. Existing entities, such as nonprofits, community foundations, and university centers, can serve backbone functions of maintaining strategic direction, communications, data management, outreach, and mobilization of funding.

Expansion of entrepreneurial opportunities and adoption of cooperative business models are frequently evoked as an important means for revitalizing agricultural and rural economies (Gladwin et al. 1989; Hamilton 2008; Sharp et al. 2002). Bioenergy specifically is touted as an opportunity for entrepreneurial activity leading to improved rural conditions (Cowan 2007; Kleinschmidt 2007) The grass-shed concept is founded on a belief that bioeconomic transitions cannot wait for major shifts in state and federal policy for broad-scale sectoral change. A critical issue for rural entrepreneurial economic development is existence of social infrastructure supporting access to information, financial resources, and technical support (Sharp et al. 2002). We believe the grass-shed approach overcomes these constraints through the collaborative processes described above.

\section{WISCONSIN GRASS-SHED EFFORTS}

Collaborators in southern Wisconsin have initiated a grass-shed for bioenergy development. The nucleus for this case is a biomass harvest experiment involving public conservation lands and multiple actors in public and private organizations. The US Fish and Wildlife Service Leopold Wetland Management District (District) manages more than 5,250 ha (12,973 ac) of Waterfowl Production Areas (WPAs) in 17 southern Wisconsin counties. These areas are near wetland basins and are managed as upland habitats, predominantly grasslands for nesting waterfowl. Fire is the preferred tool for managing WPA grassland habitats in early successional states. However, the District is unable to apply prescribed fire at the scale desired $(1,100$

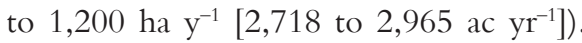
Therefore, the District is exploring late and dormant season haying as a supplemental tool for maintaining WPAs in diverse and healthy conditions. Prior to applying this practice, however, evaluation of ecological soundness and technical feasibility of WPA harvest is necessary to determine if it meets habitat management goals.

In 2011, the District and personnel of the University of Wisconsin-Madison (UW) initiated a multiyear, collaborative, landscape-scale biomass harvest experiment. The experiment involves a set of 12 WPAs in five southern Wisconsin counties where approximately $1,000 \mathrm{Mg}(1,102$ tn) of mixed grass biomass is annually harvested and the ecological and environmental impacts are being evaluated. The activities of the experiment have been organized as a joint partnership between the District and UW constrained by the legal obligations and limitations of the Fish and Wildlife Service (figure $2)$. Disciplinary expertise among partners includes wildlife ecology, grassland ecology, entomology, landscape ecology, agronomy, and agricultural economics. A team of cocoordinators, one each from the District and UW, provides overall guidance in processes of experimental design, implementation, and communications (figure 2 , panel b). Farmers, contract harvesters, and a value-added biomass agribusiness have been recruited as operations partners (figure 2, panel b).

The harvest experiment is located in a region where dairy livestock are abundant, and their densities are growing as confined animal feeding operations become more numerous. Here, dairy livestock manure is 
applied to land to manage farm nutrients. However, applications frequently exceed land capability to sequester phosphorus $(\mathrm{P})$ and nitrogen $(\mathrm{N})$. Excess $\mathrm{P}$ and $\mathrm{N}$ enter surrounding surface waters via runoff and soil erosion, leading to water quality degradation with impacts to human health and economic systems (Ridlington and Kohler 2011). Anaerobic digestion (AD) is a waste management technology that can process livestock manure and deliver a variety of coproducts including renewable energy (i.e., biogas). Perennial grasses can be used as secondary substrates in AD processes where they can improve system performance, particularly in the case of cow manure (Lehtomaki et al. 2007). Expansion of warm season perennial grasses in buffers and other configurations is gaining attention as a potential means for mitigating $\mathrm{P}$ and $\mathrm{N}$ issues (Asbjornsen et al. 2012). Thus, partners in the WPA experiment have initiated a grass-shed to improve landscape multifunctionality by coupling livestock waste, perennial grass production, and habitat conservation residuals (e.g., WPA harvest materials) through AD.

The WPA landscape experiment helped launch the southern Wisconsin grassshed effort because of the approximately $1,000 \mathrm{Mg}(1,102 \mathrm{tn})$ of mixed grass biomass available annually. These materials, it was reasoned, could be used as "seed" for expanding supply/value chains involving additional grass grown on private lands if a biomass conversion facility were located nearby. In this case, the incubation stage has involved reaching out to a limited number of strategic partners well positioned to build and operate an AD facility-including an alternative energy company and a specialty biomass agribusiness. These partners form a core that reaches out to others to expand development of the grass-shed.

To transition from incubation to start-up, a transdisciplinary leader was nominated and has begun leadership activities, and UW was chosen as the backbone organization. The transition has also involved negotiation of memorandas of understanding and exchange of nondisclosure agreements. Early in the start-up stage, collaborators identified the following primary goals:
1. a self-perpetuating, profitable AD system;

2. extramurally funded transformative research in integrated systems, bioenergy technology, economic modeling, and related subject areas;

3. expanded bioeconomic activity; and

4. restoration of ecological functions in the landscape.

They also identified their individual and collective competencies and recognized where additional expertise and knowledge may be required. These gaps are areas of potential expansion of partners and consultancy on an as-needed basis.

Collaborators are currently considering a potential AD site and have initiated a modeling exercise to evaluate alternative scenarios of supply chain development and landscape configurations of grass production. The planning process involves identification of novel incentives for grass production, such as innovative state legislation that holds point sources accountable for reduced $\mathrm{P}$ loads but allows for upstream expenditures on nonpoint source prevention (WDNR 2013), and new market incentive programs for reducing capital and operating costs for the alternative energy company. This group is also evaluating the potential for green credit stacking in which environmental payments and credits from a variety of sources may be coordinated to help support the entire enterprise of grass production coupled with dairy manure in AD.

Next steps center on alignment of actors and information necessary for finalizing the AD location, acquiring long-term contracts for dairy manure and grass biomass supply, and encouraging biogas and coproducts off-take. Beyond this lie the tasks of designing approaches to evaluation of grass-shed performance and incorporation of feedback (i.e., adaptive management), as well as prioritizing research needs and education/outreach opportunities. A high priority is being placed on the production of empirical knowledge regarding improvements to surface waters due to grass production (extent and configuration), as well as new grass supply/value chains and their impacts on existing markets and land uses.

In addition to next steps, collaborators are anticipating future opportunities for research, outreach, and replication of the collaborative approach to project development. The AD is seen as an opportunity to co-locate novel and experimental energy systems, including advanced biofuel production. This could include, for example, pilot-scale pretreatment facilities for advanced biofuels as well as a variety of gasification technologies. Biomass pretreatment facilities could utilize waste heat from the digester and benefit from economies of scale in biomass delivery and other logistical concerns (figure 3). Co-located gasifiers could process digestate from the anaerobic digester, resulting in biochar. The biochar could be used as a soil amendment in surrounding agricultural fields, or alternatively, be packaged and marketed for use elsewhere. In short and longer terms, collaborators in the southern Wisconsin grass-shed share interest in replication of the grass-shed model. In this regard they are committed to the development of communication and outreach materials along the way to help others consider new approaches to interventions for conservation and commerce benefits. They are seeking engagement with professionals in traditional extension as well as partnership with nonprofit organizations that reach across scientific, practitioner, and community groups.

\section{CONCLUSION}

If carefully planned and managed, production and marketing of perennial grasses for bioenergy and bioproducts potentially delivers conservation, amenity, and production benefits. However, market inertia resulting from uncertainty and risk has stalled development of bioeconomies. As a means of introducing strategic change, enabling research, and reducing risk and uncertainty, partners from academia, industry, resource management agencies, and nonprofit organizations have committed to the grass-shed approach in a southern Wisconsin case. Although it is a relatively new undertaking and has not been formally evaluated, the southern Wisconsin grass-shed case has served to galvanize thought and action. It has also become the focus of interest in the formation of new models of public-private partnership supported by the university. Interest is particularly keen for transferability to others so 


\section{Figure 3}

Anaerobic digester of proven technology and operating at commercial scale (Biogas LLC) could provide co-location opportunities for experimental systems of biomass preprocessing and conversion of advanced biofuels. (Photo courtesy of Todd Stradford, associate professor of social sciences, University of WisconsinPlatteville, 2008.)

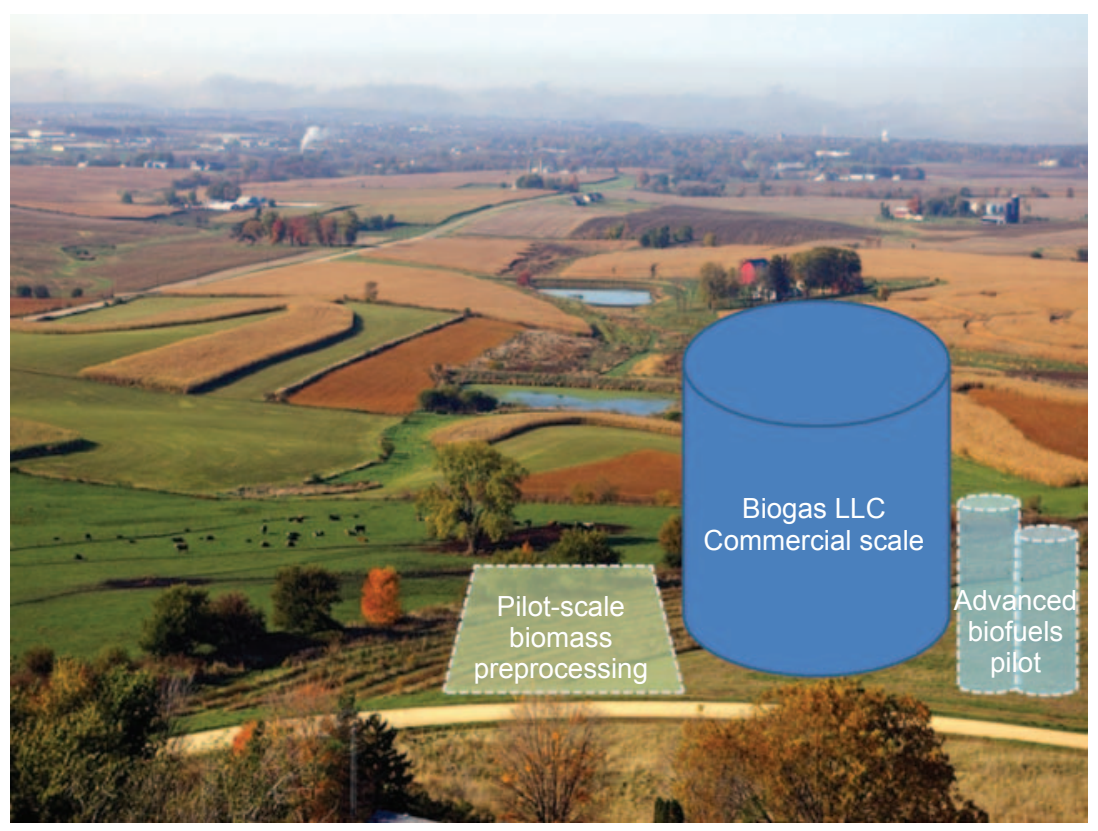

that conservation and economic interests can be mutually served. Documentation and analysis of the Wisconsin case will help inform outreach efforts.

We believe institutional researchers are uniquely positioned to serve as agents of change (Swing 2009). There is much room for their leadership in grassshed initiation and deployment over time. To do this, however, they will need to be properly motivated and equipped to lead. Researchers' institutions, therefore, must innovate appropriate systems of reward and advancement for such efforts (VegaLeinhert et al. 2009). Here, there is ample opportunity for realigning institutional capacities and norms to more fully support advancements in praxis and scholarship relevant to the grass-shed model.

\section{DISCLAIMER}

The findings and conclusions in this article are those of the author(s) and do not necessarily represent the views of the US Fish and Wildlife Service.

\section{ACKNOWLEDGEMENTS}

We thank Andy Paulios, David Williams, and Pamela Porter for their insights and comments in the early stages of this work. This work was funded in part by a University of Wisconsin College of Agriculture USDA Hatch Grant (WIS01730) and the DOE Great Lakes Bioenergy Research Center (DOE Office of Science BER DE-FC02-07ER64494).

\section{REFERENCES}

Ansell, C., and A. Gash. 2007. Collaborative governance in theory and practice. Journal of Public Administration Research and Theory 18: 543-571. Armitage, D.R., R. Plummer, F. Berkes, R.I. Arthur, A.T. Charles, I.J. Davidson-Hunt, A.P. Diduck, N.C. Doubleday, D.S. Johnson, M. Marschke, P. McConney, E.W. Pinkerton, and E.K.Wollenberg. 2009. Adaptive co-management for social-ecological complexity. Frontiers in Ecology and the Environment 7:95-102.

Asbjornsen, H.,V. Hernandez-Santana, M. Liebman, J. Bayala, J. Chen., M. Helmers, C.K. Ong, and L.A. Schulte. 2013. Targeting perennial vegetation in agricultural landscapes for enhancing ecosys- tem services. Renewable Agriculture and Food Systems epub: 25 .

Atwell, R.C., L.A. Schulte, and L.M. Westphal. 2009. Linking resilience theory and diffusion of innovations theory to understand the potential for perennial in the U.S. Corn Belt. Ecology and Society 14.

Atwell, R.C., L.A. Schulte, and L.M. Westphal. 2010. How to build multifunctional agricultural landscapes in the U.S. Corn Belt: Add perennials and partnerships. Land Use Policy 27:1082-1090.

Atwell, R.C., L.A. Schulte, and L.M. Westphal. 2011. Tweak, adapt, or transform: Policy scenarios in response to emerging bioenergy markets in the U.S. Corn Belt. Ecology and Society 16.

Austin, J.E. 2000. The collaboration challenge: How nonprofits and businesses succeed through strategic alliances. San Francisco: Jossey-Bass.

Bammer, G. 2008. Enhancing research collaborations: Three key management strategies. Research Policy 37:875-887

Barreteau, O., P.W.G. Bots, and K.A. Daniell. 2010. A framework for clarifying "participation" in participatory research to prevent its rejection for the wrong reasons. Ecology and Society 15:1.

Buccholz, T.S., T.A. Volk, and V.A. Luzadis. 2007. A participatory systems approach to modeling social, economic, and ecological components of bioenergy. Energy Policy 35:6084-6094.

Chakraborty, A. 2011. Enhancing the role of participatory scenario planning processes: Lessons from Reality Check exercises. Futures 43:387-399.

Cowan, T. 2007. Rural development and the 2007 Farm Bill. Washington, DC: Congressional Research Service.

EISA (Energy Independence and Security Act) 2007. Energy Independence and Security Act. 110th Congress Public Law 140. Washington, DC: US Government Printing Office.

Gladwin, C.H., B.F. Long, E.M. Babb, L.J. Beaulieu, A. Moseley, D. Mulkey, and D.J. Zimet. 1989. Rural entrepreneurship: One key to rural revitalization. American Journal of Agricultural Economics 71:1305-1314.

Goolsby, D.A., W.A. Battaglin, B.T. Aulenbach, and R.P. Hooper. 2001. Nitrogen input to the Gulf of Mexico. Journal of Environmental Quality 30:329-336

Gray, B. 2008. Enhancing transdisciplinary research through collaborative leadership. American Journal of Preventive Medicine 35S:S124-S132.

Hamilton, N.D. 2008. Rural lands and rural livelihoods: Using land and natural resources to revitalize rural America. Drake Journal of Agricultural Law 13:179-206. 
Hanleybrown, F., J. Kania, and, M. Kramer. 2012. Channeling change: Making collective impact work. Stanford Social Innovation Review. http://www.ssireview.org/blog/ entry/channeling_change_making_collective_impact_work? cpgn $=$ WP\%20DL\%20-\%20 Channeling\%20Change.

Hazell, P., and S. Wood. 2008. Drivers of change in global agriculture. Philosophical Transactions of the Royal Society B:495-515.

Hirsch Hadorn, G., S. Biber-Klemm, W. Grossenbacher-Mansuy, H. Hoffmann-Riem, D. Joye, C. Pohl, U. Weismann, and E. Zemp. 2008. The emergence of transdisciplinarity as a form of research. In Handbook of Transdisciplinary Research, ed. G. Hirsch Hadorn, H. Hoffmann-Riem, S. Biber-Klemm, W. Grossenbacher-Mansuy, D. Joye, C. Pohl, U. Weismann and E. Zemp. New York: Springer.

Hobbs, R.J., L.M. Hallett, P.R. Ehrlich, and H.A. Mooney. 2011. Intervention ecology: Applying ecological science in the twenty-first century. BioScience 61:442-450.

Holling, C.S., and G.K. Meefe. 1996. Command and control and the pathology of natural resource management. Conservation Biology 10:328-337.

Jordan, N., and K.D. Warner. 2010. Enhancing the multifunctionality of US agriculture. BioScience 60:60-66.

Kircher, M. 2012. The transition to a bio-economy: National perspectives. Biofuels, Bioproducts \& Biorefining 6:240-245.

Kleinschmidt, J. 2007. Biofueling rural development: Making the case for linking biofuel production to rural revitalization. Carsey Institute Policy Brief No. 5. Durham, NH: University of New Hampshire. http://www.carseyinstitute.unh. edu/publications/PB_biofuels.pdf.

Lehtomaki, A., S. Huttunen, and J.A. Rintala. 2007. Laboratory investigation on co-digestion of energy crops and crop residues with cow manure for methane production: Effect of crop to manure ratio. Resources, Conservation and Recycling 51:591-609.

Matson, P.A., and P.M. Vitousek. 2006. Agricultural intensification: Will land spared from farming be land spared for nature? Conservation Biology 20:709-710.

McCormick, K., and T. Kaberger. 2005. Exploring a pioneering bioenergy system: The case of Enkoping in Sweden. Journal of Cleaner Production 13:1003-1014.

MEA (Millennium Ecosystem Assessment). 2005. Living Beyond Our Means: Natural Assets and
Human Well-being. http://www.unep.org/ maweb/en/index.aspx.

Mollinga, P.P. 2010. Boundary work and the complexity of natural resources management. Crop Science 50:S-1-S-9.

Nassauer, J.I. 1995. Culture and changing landscape structure. Landscape Ecology 10:229-237.

Nassauer, J.I., and R.C. Corry. 2004. Using normative scenarios in landscape ecology. Landscape Ecology 19:343-356.

Perfecto, I., and J. Vandermeer. 2010. The agroecological matrix as alternative to the land-sparing/ agricultural intensification model. Proceedings of the National Academy of Sciences 107:5786-5791.

Rajagopal, D., and D. Zilberman. 2007. Review of environmental, economic and policy aspects of biofuels. Policy Research Working Paper 4341. The World Bank Development Research Group, Sustainable Rural and Urban Development Team. http://econ.worldbank.org/external/ default $/$ main?pagePK $=64165259 \&$ theSitePK= 4 $69372 \&$ piPK $=64165421 \& \mathrm{menuPK}=64166093$ \&entityID=000158349_2007090416U.S. 2607.

Ravetz, J.R. 2006. Post-normal science and the complexity of transitions towards sustainability. Ecological Complexity 3:257-284.

Ridlington, E., and D. Kohler. 2011.Wisconsin's lakes at risk:The growing threat of pollution from agriculture and development. Madison: Wisconsin Environment Research and Policy Center. http://www.wisconsinenvironment.org/sites/ environment/files/reports/Wisconsin $\% 27 \mathrm{~s} \% 20$ Lakes\%20at\%20Risk\%20web.pdf.

Schusler, T.M., D.J. Decker, and M.J. Pfeffer. 2010. Social learning for collaborative natural resource management. Society \& Natural Resources: An International Journal 16:309-326.
Shafie-Khah, M., M. Parsa Moghaddam, and M.K. Sheikh-El-Eslami. 2013. Development of a virtual power market model to investigate strategic and collusive behavior of market players. Energy Policy 61:717-728.

Sharp, J.S., K. Agnitsch, V. Ryan, and J. Flora. 2002. Social infrastructures and community economic development strategies: The case of self-development and industrial recruitment in rural Iowa. Journal of Rural Studies 18:405-417.

Solomon, B.D. 2010. Biofuels and sustainability. Annals of the New York Academy of Sciences: Ecological Economics Review 1185:119-134.

Swing, R.L. 2009. Institutional researchers as change agents. New Directions for Institutional Research 143:5-16.

Taylor, C.M., S.J. Pollards, A.J. Angus, and S.A. Rocks. 2013. Better by design: Rethinking interventions for better environmental regulation. Science of the Total Environment 447:488-499.

Tilman, D., J. Hill, and C. Lehman. 2006. CarbonNegative biofuels from low-input high-diversity grassland biomass. Science 314:1598-1600.

Vega-Leinert, A.C. de la, S. Stoll-Kleeman, and T. O'Riordan. 2009. Sustainability science partnerships in concept and in practice: A guide to new curriculum from a European perspective. Geographical Research 47:351-361.

Warner, K.D. 2008. Agroecology as participatory science: Emerging alternatives to technology transfer extension practice. Science, Technology and Human Values 33:754-777.

WDNR (Wisconsin Department of Natural Resources). 2013. Wisconsin's Phosphorus Rule. Madison, WI: Wisconsin Department of Natural Resources. http://dnr.wi.gov/topic/surfacewater/phosphorus.html. 